imaging modality available. Therefore, as the application of ultrasound expands within clinical medicine, educational considerations must also align with this expansion to maintain diagnostic accuracy. This means an increasing demand for associated education and training, including in the undergraduate tertiary education sector.

Prehosp Disaster Med 2019;34(Suppl. 1):s132-s133

doi:10.1017/S1049023X19002899

\section{From Yokohama, Hyogo, and Sendai to the World: The Global Legacy of Kobe}

Prof. Frank Archer, Dr. Caroline Spencer, Mr. Dudley McArdle

Monash University Disaster Resilience Initiative, Clayton, Australia

Introduction: The Hyogo and Sendai Frameworks for Disaster Reduction are well known and have been influential globally. However, less is known of their broader contexts.

Aim: A recent opportunity to visit Kobe, Japan, provided an opportunity to experience the rich, and largely unknown tapestry behind the scenes of the Hyogo and Sendai Frameworks. This paper aims to illuminate the journey of the Kobe Legacy and its global influence.

Methods: An experiential visit to Kobe and exploring its rich resources relating to disaster risk reduction.

Results: The First World Conference on Natural Disasters, was held in Yokohama, Japan, in 1994. Almost immediately, Kobe experienced the Great Hanshin Earthquake, January 17, 1995, resulting in 6,434 dead, 43,792 injured, and 249,180 homes damaged. The United Nations International Strategy for Disaster Reduction (2000 - 2005) culminated in the Second World Conference on Disaster Reduction, Kobe, 2005 and the Hyogo Framework for Action 2005 - 2015. The Great East Japan Earthquake occurred on March 11, 2011, with 18,453 dead or missing, 6157 injured, 1.1M homes damaged, with a tsunami and nuclear accidents. The Third World Conference on Disaster Risk Reduction followed in Sendai in 2015 with the Sendai Framework for Disaster Risk Reduction 2015 - 2030 agreed on. Subsequently, the Sendai Framework has further evolved. However, behind the scenes, Kobe has developed a rich tapestry of insightful and valuable resources which will be outlined in this presentation.

Discussion: In the words of the Mayor of Kobe, Mr. Tatsuo Yada in 2010, "I would like to reaffirm my determination to never allow our experiences of the disaster to fade away. It is our responsibility to make the utmost effort for disaster prevention and mitigation and keep passing on our experiences and the lessons learned to future generations". This is the real legacy of Kobe.

Prehosp Disaster Med 2019;34(Suppl. 1):s133

doi:10.1017/S1049023X19002905

\section{Gender-Based Violence After A Natural Disaster}

Dr. Himabindu Reddy, Dr. Annekatbryn Goodman

Massachusetts General Hospital, Boston, United States

Introduction: Gender-based violence is endemic across the world. The current evidence suggests that gender-based violence increases after natural disasters. Factors leading to this increase following natural disasters include physical displacement, loss of community supports and protections, economic hardship, and gendered differences in coping. Multiple agencies are mobilized in response to natural disasters, however, personnel are often not adequately trained to recognize or address gender-based violence.

Aim: To identify challenges faced by disaster responders in recognizing and responding to gender-based violence in disaster settings, and to advocate for gender-sensitive training prior to deployment by responding personnel.

Methods: The world's literature was reviewed to identify challenges for disaster teams in recognizing and responding to gender-based violence, and to identify principles of training which may be applicable for pre-deployment competency building by disaster response personnel

Results:

Disaster response programs should ensure:

- Collection of data to identify vulnerable populations

- Establishment of procedures for monitoring and reporting

- Inclusion of female staff at all levels of planning and response

- Implementation of holistic services including physical and psychosocial care and legal response

- Safety in designing accommodations and distribution centers

Pre-Deployment training should include:

- Gender-sensitive approach, knowledge of prevalence and impact of gender-based violence

- Familiarity with behaviors and conditions associated with gender-based violence

- Non-judgmental, supportive, and validating approach to inquiry and response

- Familiarity with risk assessment tools

- Mobilization of social supports

- Knowledge of resources, including medical and legal services

Discussion: Natural disasters are destabilizing events which expose vulnerable populations, particularly women, to increased violence. Disaster response teams should be adequately trained on the prevalence and impact of gender-based violence to ensure gender-sensitive interventions. Standard training of response personnel can ensure adequate identification of victims of gender-based violence and referral to appropriate services.

Prehosp Disaster Med 2019;34(Suppl. 1):s133

doi:10.1017/S1049023X19002917

Happy New Year! Do New Year's Eve Festivities Influence the Workload of the Emergency Department of an Urban Hospital?

Dr. Annelies Scholliers ${ }^{1,2,4}, M r$. Stefan Gogaert ${ }^{1}, M r$. Dimitri De Fré $^{1,3}$, Mrs. Inge D'haese ${ }^{1}$, Dr. Carine Vandycke $e^{4}$

1. Mass Gathering Solutions, Wambeek, Belgium

2. Department of Anaesthesiology and Perioperative Medicine, University Hospital, Free University of Brussels, Jette, Belgium

3. University Hospital Gasthuisberg, Leuven, Belgium

4. AZ Sint-Jan Brugge-Oostende, Brugge, Belgium

Introduction: Bruges is the largest city in the province of West-Flanders in Belgium. Because of its ample canals, it is sometimes referred to as "Venice of the North." As such, it is 